\title{
Rearrangement Reactions of the Molecular Ions of Some Substituted Aliphatic Oxiranes ${ }^{\dagger}$
}

\author{
Hans-Friedrich Grützmacherł and Doris Pankoke \\ Fakultät für Chemie der Universität Bielefeld, Postfach 8640, Universitätsstraße, D-4800 Bielefeld, FRG
}

\begin{abstract}
The fragmentation reactions of glycidic methyl ester (1) and of its derivatives (2-6) substituted by one, two and three methyl groups, respectively, at the oxirane ring, of the corresponding glycidols (7-12), and of the glycidyl ethers (13-16) in the $70 \mathrm{eV}$ mass spectra have been studied using isotopic labelling and mass-analysed ion kinetic energy spectrometry. It is shown that the typical reaction of these aliphatic oxirane radical cations carrying a nucleophilic methoxy group and hydroxy group, respectively, at the side chain corresponds under high-energy conditions to a rearrangement by a methoxy group or a hydroxy group migration to the $\beta$-carbon atom of the oxirane moiety. This rearrangement is very likely mediated by the isomerization of the molecular ions into distonic ions via $\mathrm{C}-\mathrm{C}$ bond cleavage within the oxirane ring.
\end{abstract}

\section{INTRODUCTION}

The electron impact (EI) mass spectra of aliphatic and aromatic oxiranes demonstrate fragmentations by extensive rearrangement reactions. ${ }^{1,2,3}$ The source of these rearrangements is probably a fast cleavage of the ring of the oxirane molecular ion yielding a reactive distonic ion. ${ }^{4}$

It is still a matter of debate whether or not the oxirane radical cation itself and its simply alkylated derivatives are kinetically stable species in the gas phase. ${ }^{5}$ In the course of our studies on the properties of electron deficient $\alpha$-acyl carbenium ions in the gas phase $^{6}$ we were interested in the direct generation of oxiranyl cations. These ions could arise from appropriately substituted oxirane molecular ions by an $\alpha$ cleavage at the oxygenated ring if the rate of this fragmentation exceeds that of a bond cleavage within the ring. This can perhaps be achieved if the substituent at the ring is a good 'mass spectrometric leaving group' which forms a stable radical after a bond cleavage. Accessible functionalized oxiranes which are stable enough for a mass spectrometric investigation are oxirane carboxylic esters (glycidic esters), hydroxymethyl oxiranes (glycidols) and alkoxymethyl oxiranes (glycidyl ethers) which give rise to stable carboalkoxy radicals, hydroxymethyl radicals and alkoxymethyl radicals, respectively, after the $\alpha$-cleavage.

The EI mass spectra of epoxyketones, ${ }^{7}$ of aromatic glycidic esters and amides, ${ }^{8}$ and of rather complex functionalized oxiranes ${ }^{1}$ have been examined in some detail but the mass spectrometric reactions of simple aliphatic glycidic esters have not been studied very much. Similarly, little information is available on the mass spectra of glycidyl ethers except for some derivatives of com-

$\uparrow$ Dedicated to Professor Allan Maccoll on the occasion of his 75th birthday.

\$ Author to whom correspondence should be addressed. mercial use. ${ }^{9}$ Therefore we investigated the unsubstituted glycidic methylester, the unsubstituted glycidol and some of its ethers as well as the derivatives of these oxiranes substituted by one, two and three methyl groups, respectively, at the ring by EI mass spectrometry using isotope labelling and mass-analysed ion kinetic energy (MIKE) spectrometry. Besides the possible formation of oxiranyl cations it was of interest to examine whether the rearrangement reactions reported earlier for aromatic epoxide derivatives ${ }^{8}$ occur also in the aliphatic series.

\section{RESULTS AND DISCUSSION}

\section{Glycidic methyl esters}

The $70 \mathrm{eV}$ mass spectra of the glycidic methyl esters (1-6) (Scheme 1) are presented in Fig. 1. The molecular peaks are very weak and can barely be detected in most of the mass spectra. This is not unexpected in view of the low intensities of the molecular ions in the spectra of simple oxiranes. ${ }^{2}$ Obviously the additional functional group at the oxirane ring enhances exceptionally the reactivity of the molecular ions $1^{+\cdot}-6^{+\cdot}$. However, the peak at $\left[\mathrm{M}-\mathrm{OCH}_{3}\right]^{+}$, typical of the mass spectra of methyl esters, is also absent whilst the peaks of the ions $m / z 59$ and $[\mathrm{M}-59]^{+}$arising from an $\alpha$-cleavage between the oxirane ring and the ester group are

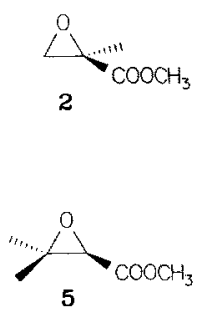

Scheme 1
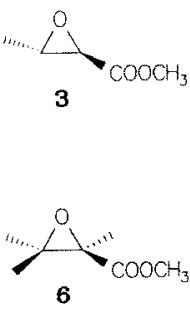

6 



Figure 1. $70 \mathrm{eV}$ mass spectra of glycidic methyl ester 1 and its methyl substituted derivatives 2-6.

observed albeit with modest intensities. Additionally the peak at $m / z 59$ in the mass spectrum of 5 is incompletely shifted to $\mathrm{m} / \mathrm{z} 62$ in the spectrum of trideuteromethyl ester 5- $d_{3}$ (Fig. 1) as expected for the ion $\mathrm{H}_{3} \mathrm{COOC}^{+}$. This indicates other sources for the ions $m / z 59$. Accordingly the $\alpha$-cleavage at the oxirane ring is not the preferred fragmentation pathway of the aliphatic glycidic ester radical cations, and these ions are inconvenient precursors to create oxiranyl cations even in the case of the trimethylated derivative 6 . Indeed the collisional activation (CA) spectra of the ions $\left[\mathrm{M}-\mathrm{COOCH}_{3}\right]^{+}$ show that these ions represent mixtures of isomeric structures. ${ }^{10}$ Hence, either the oxiranyl cations isomerize quickly into more stable structures even in the presence of stabilizing methyl substituents or the ions $\left[\mathrm{M}-\mathrm{COOCH}_{3}\right]^{+}$arise from previously isomerized glycidic ester radical cations.

The favoured pathway of the unimolecular decompositions of $1^{+\cdot}-6^{+\cdot}$ under high-energy conditions in the ion source is uncovered by the presence of large peaks 
of oxonium ions $\left[\mathrm{C}_{n} \mathrm{H}_{2 n+1} \mathrm{O}\right]^{+}$(confirmed by highresolution measurements) in the mass spectra. These ions appear at $m / z 45,59$ and 73 , respectively, in the spectra of 1 and 2,3 and 4 , and 5 and 6 . These mass shifts agree with the $\beta$-methyl substitution of the glycidic methyl ester. Additionally a complete shift of the peak at $\mathrm{m} / \mathrm{z} 73$ to $\mathrm{m} / \mathrm{z} 76$ is observed in the mass spectra of 5 and $5-d_{3}$, respectively, confirming the presence of the ester methoxy group within these ions. Thus the oxonium ions arise by a methoxy group migration and their structure corresponds to $a$ (Scheme 2). This result shows conclusively that the formation of ions of type $a$ by a rearrangement of the glycidic ester molecular ions is not restricted to aromatic derivatives ${ }^{8}$ but also occurs even in the mass spectrum of the unsubstituted glycidic ester (1). Nonetheless a substitution at the $\beta$-position which should favour the cleavage of the oxirane ring and a localization of the positive charge at the $\beta$-carbon atom also favours the formation of the rearrangement oxonium ions whilst a substitution at the $\alpha$-position directs the fragmentations into other reactions channels (i.e. eventually the formation of $\mathrm{CH}_{3} \mathrm{CO}^{+}$). This can be easily recognized by comparing the mass spectra of 1 and 2,3 and 4, and 5 and 6, respectively. This agrees
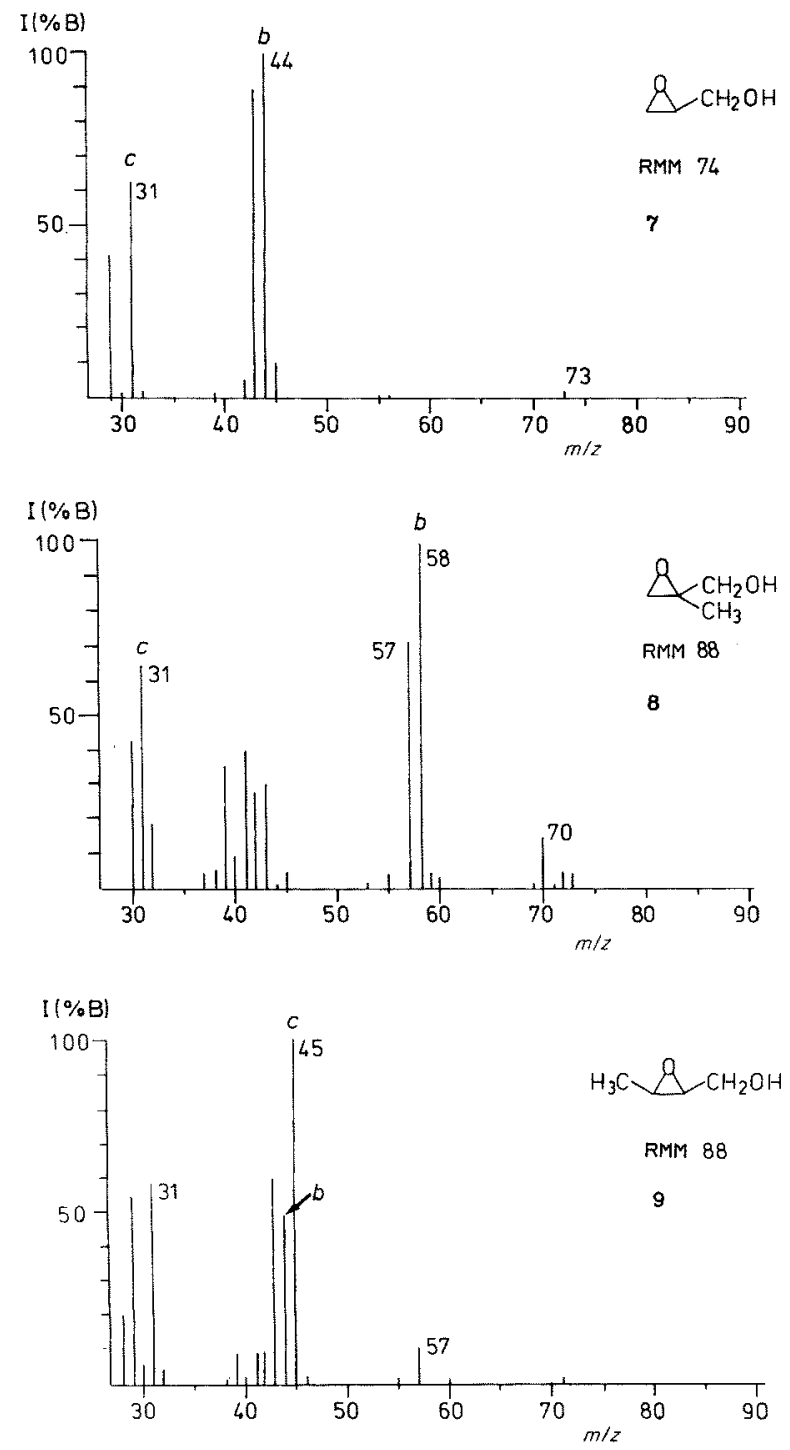

Figure 2. $70 \mathrm{eV}$ mass spectra of glycidols 7-12.

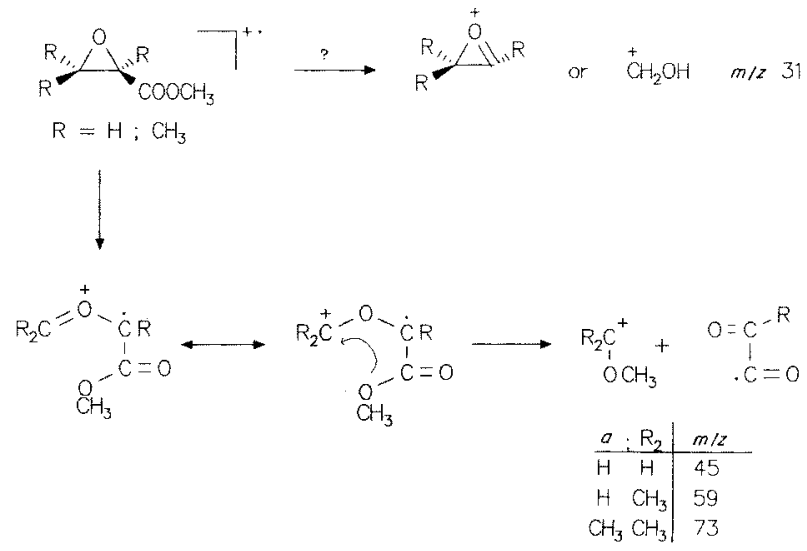

Scheme 2

with the mechanism depicted in Scheme 2 where the nucleophilic methoxy group migrates towards the electron deficient carbenium ion centre of the intermediate distonic ion, and the formation of this latter isomer of the glycidic ester molecular ion is very likely to be the critical reaction step.

In spite of the low intensity of the molecular ions it
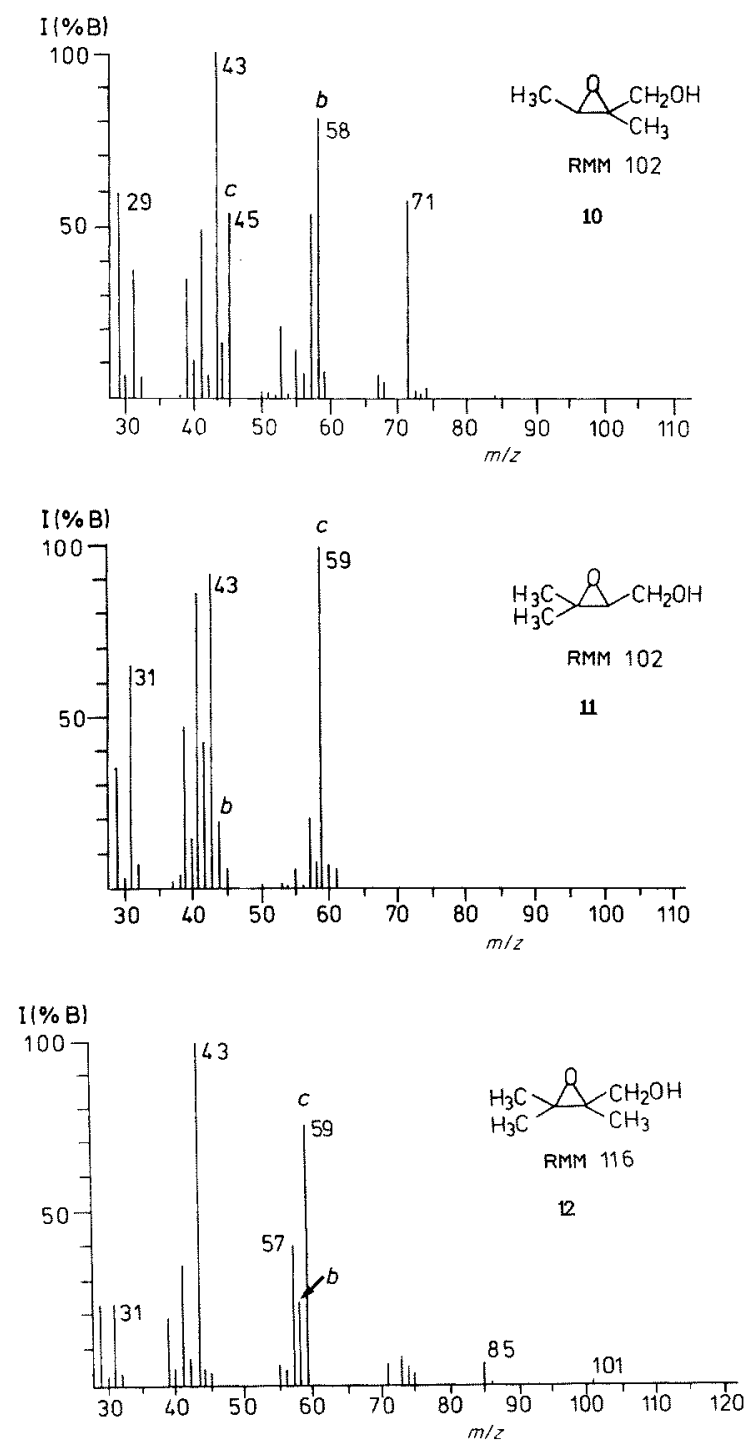
Table 1. Partial mass spectra ${ }^{*}$ of OD-deuterated glycidols 7-12,ce

\begin{tabular}{|c|c|c|c|c|c|c|c|c|c|c|c|c|}
\hline \multirow[b]{2}{*}{$m / z$} & \multicolumn{2}{|c|}{7} & \multicolumn{2}{|c|}{8} & \multicolumn{2}{|c|}{9} & \multicolumn{2}{|c|}{10} & \multicolumn{2}{|c|}{11} & \multicolumn{2}{|c|}{12} \\
\hline & $\mathrm{OH}$ & $O D$ & $\mathrm{OH}$ & $O D$ & $\mathrm{OH}$ & $O D$ & $\mathrm{OH}$ & $O D$ & $\mathrm{OH}$ & $O D$ & $\mathrm{OH}$ & $O D$ \\
\hline 41 & - & - & & & 3 & 4 & 9 & 13 & 33 & 34 & & \\
\hline 42 & 4 & 4 & & & 4 & 2 & 5 & 9 & 13 & 21 & & \\
\hline 43 & $d 45$ & 53 & & & 28 & 26 & 56 & 40 & 48 & 28 & & \\
\hline 44 & b 47 & 14 & & & b 21 & 6 & 1 & 10 & b 4 & 9 & & \\
\hline 45 & 4 & 29 & & & c 44 & 27 & c 28 & 7 & 2 & 5 & & \\
\hline 46 & - & - & & & - & 34 & - & 22 & - & 3 & & \\
\hline 55 & & & - & - & 16 & 5 & 9 & 7 & 2 & 5 & 4 & 3 \\
\hline 56 & & & - & - & 4 & 8 & 4 & 4 & 1 & 4 & 2 & 3 \\
\hline 57 & & & $d 41$ & 19 & $d 63$ & 41 & 33 & 3 & 15 & 1 & 27 & 11 \\
\hline 58 & & & $b 55$ & 38 & 3 & 32 & $b 49$ & 35 & 5 & 15 & b 14 & 12 \\
\hline 59 & & & 1 & 40 & 3 & 12 & 5 & 47 & $c 74$ & 16 & $c 51$ & 27 \\
\hline 60 & & & 3 & 2 & 11 & 2 & - & 4 & 2 & 58 & 1 & 43 \\
\hline 71 & & & & & & & $d 93$ & 8 & $d 65$ & 31 & & \\
\hline 72 & & & & & & & - & 81 & 29 & 45 & & \\
\hline 73 & & & & & & & - & 2 & 6 & 19 & & \\
\hline 74 & & & & & & & 7 & - & - & 5 & & \\
\hline 75 & & & & & & & - & 9 & - & - & & \\
\hline 84 & & & & & & & & & & & 13 & 8 \\
\hline 85 & & & & & & & & & & & $d 60$ & 48 \\
\hline 86 & & & & & & & & & & & 25 & 28 \\
\hline 87 & & & & & & & & & & & 1 & 16 \\
\hline
\end{tabular}

a Relative intensity normalized to peak group $m / z 41-46, m / z 55-60, m / z 71-75$, and $m / z$ 84-87, respectively.

b The approximate D-label content has been determined from the shift of $m / z 31: 7,70 \% ; 8,70 \% ; 9,78 \% ; 10,78 \% ; 11,82 \% ; 12,77 \%$.

${ }^{c} b$, enol radical cation; $c$, rearrangement ion; $d$, fragment ion $[\mathrm{M}-31]^{+}$; see text.

was possible to obtain MIKE spectra from $1^{+\cdot}-5^{+*}$, although with rather bad signal-to-noise ratios. The signals detected correspond to the loss of $\mathrm{CH}_{3}{ }^{\circ}$, the elimination of $\mathrm{CH}_{3} \mathrm{OH}$ and the formation of ions $\mathrm{m} / \mathrm{z}$ 59 and 60 , respectively, but not to the formation of ions $a$. Therefore the generation of ions $a$ is not one of the energetically favoured fragmentations of the aliphatic glycidic ester molecular ions. Similarly, but in contrast to the mass spectrometric behaviour of $\beta$-phenylglycidic amides, ${ }^{8}$ a formation of immonium ions akin to the ions $a$ by a migration of the amino group has not been observed in the EI mass spectra and in the MIKE spectra of aliphatic glycidic amides. ${ }^{11}$ The reason for this is not evident but it is very likely that a distonic ion with the essential charge localization at the $\beta$-carbon atom is not formed because of a different charge distribution in the amide molecular ion.

\section{Glycidols}

The $70 \mathrm{eV}$ mass spectra of the glycidols 7-12 (Scheme 3) are shown in Fig. 2. In addition the OD-derivatives of 7-12 (obtained by exchange with $\mathrm{D}_{2} \mathrm{O}$ ) and $9-^{18} \mathrm{O}$ labelled at the hydroxy group have been investigated.

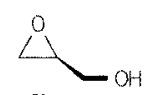

7

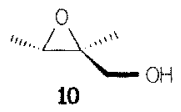

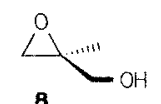

B

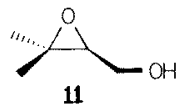

Scheme 3
The peaks of the molecular ions are not detected as anticipated for the mass spectra of functionalized aliphatic alcohols. Surprisingly, however, the peak at $\left[\mathrm{M}-\mathrm{H}_{2} \mathrm{O}\right]^{+\cdot}$ is also missing or of very low intensity, demonstrating that the instability of the glycidol radical cations is also due to a high reactivity of the oxirane moiety and not to fragmentations within the side chain. The variations in the peak pattern by the degree and positions of the methyl substitutents of 7-12 and the peak shifts observed in the mass spectra of the labelled derivatives (Table 1) establish the main fragmentation routes of the molecular ion depicted in Scheme 4.

The $\alpha$-cleavages at the oxirane ring give rise to the fragment ions $\mathrm{HOCH}_{2}{ }^{+}, m / z 31$, with moderate intensities and apparently the counter ions $[M-31]^{+}$are also formed. However, most of these ions $[M-31]^{+}$ are shifted by $1 \mathrm{u}$ in the spectra of the OD-derivatives (Table 1) and unexpectedly retain at least the hydrogen atom of the hydroxy group. Interestingly, the mass spectrum of $9-{ }^{18} \mathrm{O}$ shows much less incorporation of the ${ }^{18} \mathrm{O}-$-label into the ions $[\mathrm{M}-31]^{+}$so that extensive $H / D$ exchange preceeds obviously this fragmentation. In any case the ions $[M-31]^{+}$cannot arise by the loss of the hydroxymethyl substituent in a simple $\alpha$-cleavage process and it is doubtful whether their structures correspond to oxiranyl cations.

The second main reaction path of the fragmentation of $7^{+*}-12^{+*}$ gives rise to enol radical cations, $b, m / z 44$ and 58 , respectively, by loss of the $\beta$-carbon atom with its substituent, as shown by the appropriate shifts of the peaks in the spectra of the labelled compounds. The formation of an enol ion, $m / z 44$, from $7^{+}$has been reported $^{12}$ and is assumed to be mediated by a distonic ion (Scheme 4). Finally, strong peaks due to the 




Scheme 4

oxonium ions, $c$, expected from a hydroxy group migration to the $\beta$-carbon atom within the distonic ion are observed. These ions coincide with the $\alpha$-cleavage ion $\mathrm{HOCH}_{2}{ }^{+}$in the case of 7 and 8 but are clearly separated in the spectra of the remaining $\beta$-methylated glycidols and exhibit the expected mass shift in the spectra of the OD-derivatives (Table 1). Considering the degree of ${ }^{18} \mathrm{O}$-labelling $(38 \%$, determined from the ions $\left[\mathrm{M}-\mathrm{CH}_{3}\right]^{+}$in the mass spectrum of the O-TMS ether) at least $70 \%$ of the $m / z 45$ ions in the spectrum of 9 are shifted to $m / z 47$ in the case of $9-{ }^{18} \mathrm{O}$, in accordance with the migration of a complete hydroxy group.
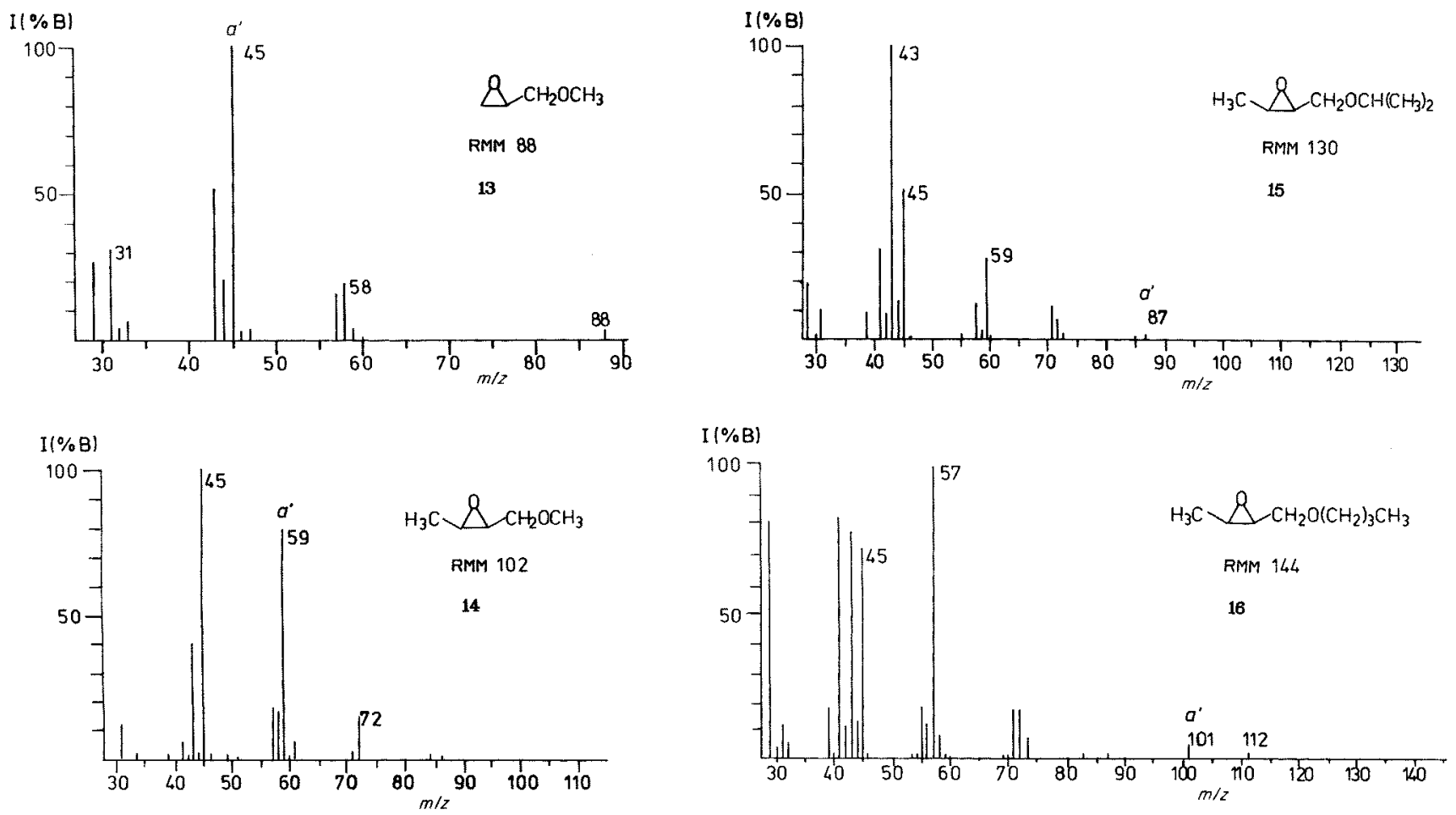

Obviously a minor amount of the $m / z 45$ ions is generated by a different mechanism, very likely by a hydrogen migration after a $\mathrm{C}-\mathrm{O}$ bond cleavage within the oxirane ring of the molecular ion. Nonetheless, the results establish clearly the migration of the hydroxy group of the side chain to the $\beta$-carbon atom as one of the main reactions of glycidol radical cations. This fragmentation can be perceived easily by assuming an intermediary distonic ion with location of the positive charge at the $\beta$-carbon atom.

\section{Glycidyl ethers}

It may be anticipated from the results discussed so far that the mass spectra of aliphatic glycidyl ethers will exhibit distinct peaks of oxonium ions arising from a migration of the alkoxy group; and this is indeed confirmed by the $70 \mathrm{eV}$ mass spectra of the ethers 13-16 (Scheme 5 and Fig. 3).

The rearrangement ion is concealed by the product ion $m / z \quad 45$ of the $\alpha$-cleavage in the mass spectrum of 13 but the spectrum of the $\beta$-methylated glycidyl ether (14) exhibits a large peak of the rearrangement ion at $\mathrm{m} / \mathrm{z}$ 59 . Hence the fragmentation by methoxy group migration competes effectively with the $\alpha$-cleavage of the
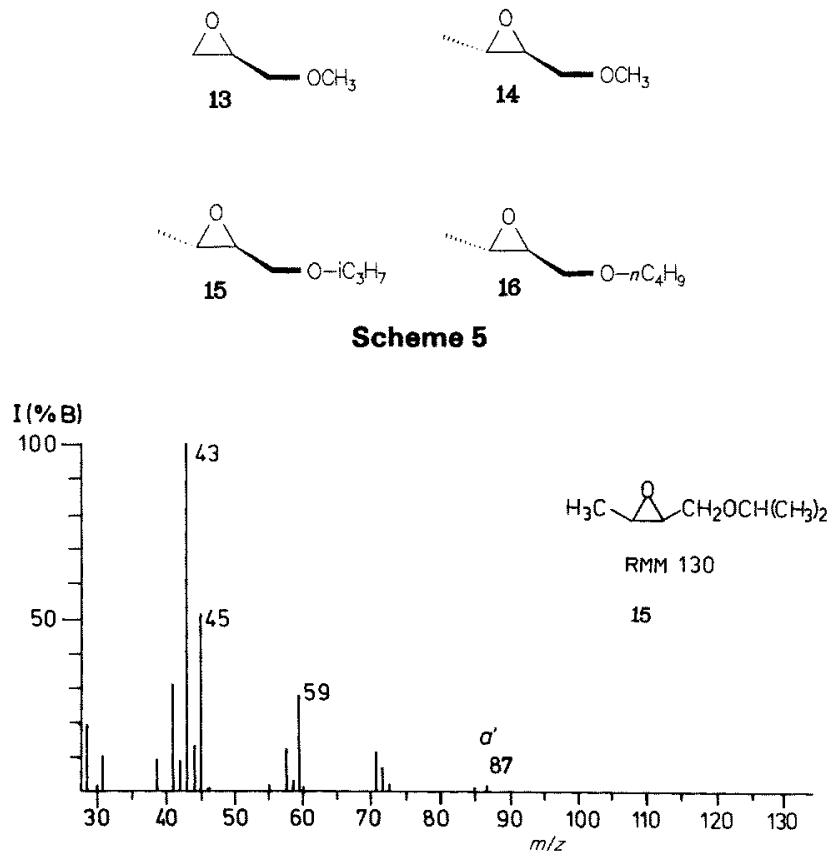

Figure 3. $70 \mathrm{eV}$ mass spectra of glycidyl ethers 13-16. 
molecular ion. Note, however, that the peaks due to both processes are rather weak in the mass spectra of the isopropyl ether (15) and $n$-butyl ether (16), respectively, and that both spectra are dominated by the alkyl ion derived from the alkoxy group. The loss of an aldehyde molecule or a ketone molecule, respectively, from alkylated oxonium ions is well documented. ${ }^{13}$ Thus the fragment ions arising from the $\alpha$-cleavage as well as those formed by alkoxy group migration in an intermediary distonic ion decompose eventually into the alkyl ions.

\section{EXPERIMENTAL}

\section{Mass spectrometry}

The $70 \mathrm{eV}$ EI mass spectra of all compounds except 7 and 13 were recorded with a GC/MS system Finnigan MAT 1020B. The samples were dissolved in diethyl ether and introduced into the system using a GC column OV 1 with $\mathrm{He}$ as the carrier gas. The $70 \mathrm{eV} \mathrm{EI}$ mass spectra of 7 and 13 were obtained with a Finnigan MAT 311A mass spectrometer combined with a MAT SS200 data system with introduction by the heated inlet system at $180^{\circ} \mathrm{C}$.

The MIKE spectra were run on a VG ZAB $2 \mathrm{~F}$ mass spectrometer using a modified heated direct inlet system and the following conditions: electron energy $70 \mathrm{eV}$, trap current $100 \mu \mathrm{A}$, ion source temperature $\sim 180^{\circ} \mathrm{C}$, acceleration voltage $6 \mathrm{kV}$. The relevant ions were focused magnetically into the second field-free region preceding the electrostatic analyser (ESA) and the daughter ions were recorded by varying the ESA voltage. The CA spectra were obtained by the same conditions but introducing $\mathrm{He}$ into the collision cell of the second field-free region at such a rate that the intensity of the main beam was reduced to $\sim 30 \%$ of its original intensity.

\section{Compounds}

The purity of all compounds has been controlled by gas chromatography and their structures have been verified by ${ }^{1} \mathrm{H}-\mathrm{NMR}$ spectrometry. The glycidic methyl esters (1-6) were synthesized by an epoxidation of the corresponding unsaturated methyl carboxylates using standard techniques. ${ }^{14}$ The unsaturated carboxylic esters were either commercially available or have been prepared from the appropriate ketones via a WittigHorner reaction. ${ }^{14}$ Trideuteromethyl 3-methyl-but-2ene carboxylate (precursor of 5- $d_{3}$ ) was obtained by reaction of $\mathrm{CD}_{3} \mathrm{OH}$ with the corresponding carboxylic chloride. $^{14}$

The glycidol 7 is commercially available. The ring methylated derivatives $8-12$ were prepared by epoxidation of the corresponding allyl alcohols ${ }^{14}$ which were obtained by the $\mathrm{LiAlH}_{4}$ reduction of the unsaturated carboxylic acids or esters in diethyl ether. ${ }^{14}$ The deuterated glycidols 7-OD-8-OD labelled at the hydroxy group were obtained by $\mathrm{H} / \mathrm{D}$ exchange with $\mathrm{D}_{2} \mathrm{O}$ in the ion source of the MAT 311A mass spectrometer (for labelling degree see Table 1).

The ${ }^{18} \mathrm{O}$-labelled 3 -methylglycidol $\left(9-{ }^{18} \mathrm{O}\right)$ was prepared from crotonaldehyde- ${ }^{18} \mathrm{O}$ and crotyl alcohol- ${ }^{18} \mathrm{O}$, respectively: $2 \mathrm{~g}(17.2 \mathrm{mmol})$ of pure crotonaldehyde dimethylacetal ${ }^{15}$ were treated with $0.25 \mathrm{~cm}^{3}(13.2$ $\mathrm{mmol}) \mathrm{H}_{2}{ }^{18} \mathrm{O}\left(50 \%{ }^{18} \mathrm{O}\right)$ and a drop of dilute $\mathrm{HCl}$. The mixture was stirred at room temperature overnight and the crotonaldehyde- ${ }^{18} \mathrm{O}$ was distilled at reduced pressure; yield $0.71 \mathrm{~g}(9.96 \mathrm{mmol}, 56 \%)$. The $\mathrm{LiAlH}_{4}$ reduction of the aldehyde to the crotyl alcohol- ${ }^{18} \mathrm{O}$ and the epoxidation to $9 .{ }^{18} \mathrm{O}$ were performed by standard methods. ${ }^{14}$ The labelling degree of $9{ }^{18} \mathrm{O}$ was determined mass spectrometrically by GC/MS after trimethylsilylation of the alcohol $(10 \mu l)$ with $20 \mu l$ bis-TMS-acetamide at $60^{\circ} \mathrm{C}$. The ${ }^{18} \mathrm{O}$-content of 35 mol $\%$ was determined from the peak doublet at $\left[\mathrm{M}-\mathrm{CH}_{3}\right]$ after a correction for ${ }^{13} \mathrm{C}$ and the $\mathrm{Si}$ isotopes. The glycidyl alkyl ethers $13-16$ were synthesized from the corresponding allyl ethers ${ }^{16}$ by the usual epoxidation. ${ }^{14}$

\section{Acknowledgements}

The financial support of this work by a grant from the Deutsche Forschungsgemeinschaft and by the Fonds der Chemischen Industrie is gratefully acknowledged. We thank Mr E. Gärtner for the assistance during the mass spectrometric measurements.

\section{REFERENCES}

1. Q. N. Porter, Mass Spectrometry of Heterocyclic Compounds, 2nd Edn, Ch. 1, Wiley, New York (1985).

2. P. Brown, J. Kossanyi and C. Djerassi, Tetrahedron Suppl. No. 8, $241(1966)$

3. M. Fetizon, Y. Henry, G. Aranda and H.-E. Audier, Org. Mass Spectrom. 8, 201 (1974).

4. B. F. Yates, W. J. Bouma and L. Radom, Tetrahedron 42, 6225 (1986).

5. G. Bouchoux, F. Djazi, Y. Hoppilliard, P, Jaudon and N. Nouts, Org. Mass Spectrom. 23, 33 (1988), and refs. cited therein.

6. R. Wolf and H.-Fr. Grützmacher, New J. Chem. 12, 865 (1988) and refs. cited therein.

7. W. Reusch and C. Djerassi, Tetrahedron 23, 2893 (1967)

8. J. Baldas and Q. N. Porter, Austr. J. Chem. 20, 2655 (1967).
9. R. M. Brown and C. S. Creaser, Org. Mass Spectrom. 15, 578 (1980).

10. D. Pankoke, Diplomarbeit, Universität Bielefeld (1987).

11. D. Pankoke, T. Hohberg and H.-Fr. Grützmacher, unpublished results.

12. J. L. Holmes and J. K. Terlouw, J. Canad. Chem. 53, 2076 (1975).

13. H. Budzikiewicz, C. Djerassi and D. H. Williams, Mass Spectrometry of Organic Compounds, Holden-Day, San Francisco (1967).

14. Th. Eicher and L. F. Tietze, Reaktionen und Synthesen im organischchemischen Praktikum, Thieme, Stuttgart (1981).

15. J. A. VanAllan, Org. Synthesis 32, 5 (1952).

16. Houben-Weyl Methoden der Organischen Chemie (Ed. E. Müller), Thieme Stuttgart (1965). Vol. 6/3,11 ff. 